\title{
The Identity of the Digital Generation of Russians: The Impact of Information and Network Resources
}

\author{
${ }^{1}$ Olga.A. Maximova, ${ }^{2}$ Maria. Iu. Eflova, ${ }^{3}$ Anastasiya A. Kulcha \\ ${ }^{1}$ Associate Professor, Department of General and Ethnic Sociology, Kazan Federal University \\ ${ }^{2}$ Professor, Department of General and Ethnic Sociology, Kazan Federal University \\ ${ }^{3}$ Graduate Student of the Second Year, Department of General and Ethnic Sociology, Kazan Federal University \\ Email:olga_max@list.ru
}

\section{Received: 02 ${ }^{\text {nd }}$ November 2018, Accepted: $28^{\text {th }}$ November 2018, Published: $31^{\text {st }}$ December 2018}

\begin{abstract}
The analysis of the specifics of the formation of the identity of the digital generation of Russian youth is carried out in the context of the impact on it of information and network resources. Based on the results of a comprehensive sociological research conducted using qualitative and quantitative methods, it was concluded that the majority of the young generation are carriers of mosaic identity. The ambivalent role of the Internet has been revealed, which has both positive and negative effects on the socialization of the digital generation.
\end{abstract}

\section{Keywords}

Information Society, Identification, Mosaic Identity, Virtual Reality, Digital Generation

\section{Introduction}

In the conditions of the information society, access to information and knowledge becomes the main of the most important factors in the formation of an individual's identity, and information and network resources become the leading agents of socialization. These dynamic agents using the latest technologies (both in technological and humanistic aspects) affect, first of all, the values and consciousness of young people, characterized by researchers as the "digital generation" $[1 ; 2 ; 3]$. Often, researchers record and the fact of manipulation of the consciousness of young people through information flows in the media [4].

At the same time, in a post-industrial, informational society, the family loses the function of a leading socializing agent, which leads to the emergence of an intergenerational gap, which takes an extreme form in the form of a generational conflict or a "gap" (Generational gap) between generations [5].

In such conditions, the older generation loses the ability to influence children in the framework of family socialization, and its influence is effectively replaced by information-network resources [6].

Each channel of mass communication through specific information network technologies demonstrates, and often imposes on the audience, its own interpretation of the images and behavioural strategies of various social agents and events. As a result, the sociocultural space is structured in the course of external identification and stigmatization of social groups, the construction of virtual communities and, as a result, the formation of one's own internal identity takes place in the process of the daily life of the digital generation.

These facts determine the relevance of the researchers appeal to the analysis of the specifics of the formation of the identity of young people in the context of the impact on the process of information network resources.

\section{Methods}

The research team with the participation of the authors of the article in September-November 2017 implemented a comprehensive sociological study using quantitative and qualitative methodology, which included the following steps: A representative survey of the youth of one of the Russian regions - the Republic of Tatarstan ( $\mathrm{N}=1241$ people). The obtained data was processed and analyzed using the program for statistical data processing - SPSS;

- a series of in-depth narrative interviews with representatives of different generations of Tatarstan people (altogether 20 interviews were conducted), processed as a narrative analysis;

- narrative essays of the younger generation $(\mathrm{N}=350)$;

- three focus groups with active Internet users;

- meaningful analysis of the messages of young users of Internet resources.

\section{Results and Discussion}

As shown by the results of the study, modern Russian youth can definitely be attributed to the digital generation, not excluded from the global trends of informatization. The results of our study can also be compared with the typology of generations proposed by Howe and Strauss, according to which new digital generations are the Millennium generation or generation Y, born in the period 1982-2004, and generation Z, born after 2005 [7]. Representatives of these generations, in our opinion, can be characterized as "digital generation", since their socialization takes place under the influence of the digital environment. But if generation $\mathrm{Y}$ in the Russian context began to master digital technologies in adolescence (since the 1990s), then the Russian generation $\mathrm{Z}$ has similar technogenic socialization conditions with Western countries. 
According to the results of the survey, $96.2 \%$ of young respondents surveyed go online daily. At the same time, about a quarter $(22.9 \%)$ of respondents spend most of their time on the Internet, $35.9 \%$ spend from 5 to 7 hours daily, and $37.2 \%$ spend from 1 to 3 hours. Thus, it can be stated that young people are deeply immersed in virtual reality.

Information network resources are a special tool for creating intellectual leadership ("thought leadership") in the Internet audience. Information in the digital space is most effectively spread through the so-called "opinion leaders" (opinion leaders, trendsetters, infensors, ambassadors, it-girls, etc.). Famous personalities often appear in this role: successful businessmen, bloggers, celebrities, musicians, actors, athletes, etc. Analysis of various information and network resources has shown that among Russian young people the most popular Western trendsetters are: Musk, D. Beckham, Rihanna, K.Vest, the Kardashian family and others, and from the Russian influencers: Y. Dud, I. Urgant, Oksimiron, N. Sobolev, E. Krid, O. Buzova and others.

This trend of personification of information delivered through mass media channels is most responsive to the youth audience, which, by virtue of age, is prone to seeking self-identification. The activity of these "leaders", both in the virtual space and in reality, gathers crowds of fans and social media subscribers around them, they are the benchmark for their audience, and their opinions are heeded. Thus, the emerging minds of young people are effectively manipulated, their values are imposed on them, up to and including the promotion of certain ideas, ways of selfexpression and lifestyle

Focus group participants noted that they encountered in personal practice the discrepancy between real and socially attractive virtual images of individuals: "You see one person on the Internet, and you encounter him in life - he behaves completely differently, I don't like it very much" (Informant focus group 1, male.). "In the Instagram ... You see how a person supposedly lives luxuriously, etc., he shows himself so rich, beautiful, and you meet in life - he is absolutely ordinary and he even has nothing to talk about ..." (informant focus group 2 females

It is worth noting the important distinctive features of the activity of individuals in the digital space: access to diverse information from different channels and the polyvalence of personal choice, both in the preferences of sources and topics of information, and in how to respond to it. In other words, a young man has alternatives: mindlessly following one "hero of the day", or fanatically copying another "it-girl", and there is an option - by filtering and analyzing information and different points of view, to form his personalized opinion, position, identity.

Opinions of focus group participants confirm this thesis: "The Internet is a fairly good source of information, because it cannot be moderated completely. Accordingly, it is impossible to control any information and I can find out exactly what I need, and not what is imposed on me ..." (informant of focus group 3, male.).

Informants also identified different strategies for the activity of young people in the digital space: "There is plenty of garbage, of course. That is, if you have a head on your shoulders, you understand what you are looking at. But, unfortunately, there are a lot of people who are watching, in my opinion, complete nonsense ... " (informant focus group 1, male.). "Well, yes, if you look at something selectively, then you put more effort into it, you begin to ponder, realize, read what you need. And when you just want to relax, you just leaf through, leaf through and that's it ... " (informant of focus group 4, male.)

It is important to note that representatives of the "digital generation" still share the reality and the virtual world, highlighting the merits of "live" communication. "The Internet plays a more entertaining role, so rewriting Vkontakte takes me a little time... If you just want to feel the person, touch him, then of course it's better to meet with close friends I'm doing so, I meet in person" (informant focus group 5, female); "Depending on what the purpose of communication is ... If I start a conversation in order to learn something about learning, it's better to write ... and in person, it's necessary to communicate face-to-face, that is, not with the help of the Internet or even Skype, but better in a cafe or somewhere else" (informant focus group 6, male.)

The growing diversity of differentiating signs leads to transformations in the format of personal identities of young people. Potentially, a whole range of alternatives to constructing multiple identities is opened up to them by finding "their" socio-cultural forms. According to the concept of E. Goffman, an amorphous identification situation "requires the development of abilities for social mimicry, the acquisition of the appearance that would be most desirable and effective in this situation" [8].

As shown by the results of our research, the majority of representatives of the younger generation of Russians are carriers of a mosaic marginal identity. This is demonstrated, for example, by self-categorization when responding to focus group informants on the question "Who am I?": "A student of a beautiful university — his favourite son — a representative of his state"; "A writer — a bodybuilder — a teacher in mathematics," "a little dancer — a little journalist — I study a programmer," etc.

The peculiarity and, at the same time, the advantage of mosaic self-identification, is its lability. Because of this, it is comfortable for young people in terms of adaptation and maintaining the social usefulness of the individual.

And it is the information-network resources that allow maintaining this lability, allowing the young user to quickly switch from one community to another, change Internet pages and communication channels. Thus, according to the results of a mass survey, the overwhelming majority of respondents daily communicate in chat rooms and social networks with friends $(88.2 \%)$, more than half $(55.7 \%)$ use the Internet to search for information and information needed for study / work, $50.6 \%$ refer to entertainment information - downloading music, watching movies, etc. Almost all respondents (99.5\%) are registered and regularly use the social network Vkontakte, more than half $(60.2 \%)$ use Instagram, about half are registered (44.5\%), but less actively communicate (23\%) in Telegram. Also, a third of the 
respondents are registered (32.3\%), but social networks such as Google+ (7.1\%) and Facebook (3.8\%) do not often visit.

\section{Summary}

If we follow the concept of self-categorization by J. Turner [9], the features of the behaviour strategy of young people in the virtual space can be interpreted as follows. According to this concept, the level of self-categorization and the subsequent self-identification of the individual varies depending on the social context of the individual's life activity. Moreover, the manifestation of the social and personal levels of self-categorization demonstrates a reciprocal relationship. As a result, the actualization of social identity inevitably suppresses attitudes and behaviour generated by personal identity, and vice versa. It was experimentally established that a high level of social self-identification of a person leads to the depersonalization of perception and produces group behaviour.

In the modern information society, on the contrary, there is a decrease in the level of social self-categorization and a parallel increase in the level of personal self-identification of individuals. Accordingly, this is accompanied by such phenomena as hyperpersonalization and the desocialization of relations in society.

As a result, in accordance with the theory of social identity of J. Turner, the interactions of individuals are mostly determined not by formal sociostatus signs (status, "group" behaviour), but by individual personal characteristics ("interpersonal behaviour").

As Tapscott and Williams point out, the Internet transforms the life of the younger generation "into a constant mass collaboration, which is incredibly popular with this generation. They cannot even imagine a life in which citizens do not have the tools for critical thinking, exchanging points of view, clarifying, identifying or exposing deception. If their parents were passive recipients of information, young people are active creators of media content and have a passion for interaction" [10].

In this connection, the problem of understanding by the youth itself of the degree of influence of information network resources on it is of significance. So, to the question "Do you agree with the statement that the Internet and social networks carry certain threats to society?", The respondents' answers were distributed as follows. Only $15.6 \%$ believe that the Internet and social networks have a negative impact on the psyche of young people, provoke an increase in suicide, terrorism, and $9.8 \%$ believe that they contribute to undermining the stability in society, provoke riots. At the same time, $39.5 \%$ believe that the harm of information network resources is that they separate a person from real life. At the same time, half of the respondents $(47.5 \%)$ do not see serious threats in the spread of the Internet and social networks.

Many young people admit that they have found an accessible, comfortable niche on the Internet for a kind of "mental relaxation" and rest from the "eternal race" in a technogenic society. "It's like watching TV, you're watching, you don't think about anything, you look through all sorts of pictures - and everything, you relax ..." (informant of focus group 7, male.) study, I rest on the Internet, or when I feel very bad, I resort to the same series and for me it is such a relaxation ..." (focus group participant 8 , female).

Cyber-space, eliminating the remote interpersonal barriers, provides endless opportunities for communication, opening the world to people, and people to the world: "And here you sit, see the Internet for the first time and immediately think - what to find out? Just like the discovery of new horizons ... there I began, I remember, to drive in the "10 best cities of the world", "the most beautiful places" ... and you watch all this, because you cannot find all this in books and magazines, but everything is before you, Answers to your questions, you learn the whole world on the Internet, you don't need to go somewhere, it's very interesting ... "(focus group informant 9, female); "There you get information both for studies and for development. Then there is also information about the world in general, you browse Twitter and some radio stations there. Then you flip through the tape that friends, relatives, mother write ... "(informant focus group 4, male.)

It represents a special significance and the problem of the respondents understanding the dangers of the Internet and information network resources that have become a familiar environment for the daily practices of young people. So, to the question "Do you agree with the statement that the Internet and social networks carry certain threats to society?" (You could choose no more than two answers) chose the answer "Yes, they negatively affect the psyche of young people, provoke an increase in suicides, terrorism "15.6\% of respondents, "Yes, they contribute to the undermining of stability in society, contribute to mass unrest"- 9.8\%. 39.5\% noted purely social harm (the option "Yes, they separate a person from real life"). At the same time, $47.5 \%$ of young respondents do not see serious threats in the spread of the Internet and social networks.

However, one can hardly deny the positive changes in the thesaurus and the speed of its replenishment among young people, thanks to the communication in networks and search engines. This is noted and interviewed. So, if you meet a new concept or term, then it will be typed in the search engine (Yandex, Google, etc.) by the overwhelming majority of the young people surveyed $(97 \%)$, every fifth $(21 \%)$ will turn to friends or friends for help, about the same the proportion of young people (18\%) will ask for help from adults (parents, teachers, etc.), and only a small proportion of young Tatarstanians (3.8\%) need to look for an unfamiliar concept, a term in books, encyclopaedias available at home and even more go to the library $(0.9 \%)$. It is obvious that printed sources of information do not enjoy such popularity as Internet resources among young people. 


\section{Conclusion}

Thus, we can assert the undoubted importance of information and network technologies in the daily practices of the modern young generation of Russians. In fact, virtual reality has become a field for constructing the everyday life of the young generation, its special characteristic that separates the digital generation from the older generations In the modern information society, including the Russian one, representatives of the digital generation are expanding the possibilities of individual alternative choice among various identification patterns in the polyvalent Internet space. In the process of forming their identity, individuals can freely "migrate" across a variety of available socio-cultural fields and arbitrarily construct their multiple personal identities based on formalized, traditional (citizenship, ethnic, professional, family, belonging, etc.) and informal ones, virtual signs.

\section{Acknowledgements}

The work is performed according to the Russian Government Program of Competitive Growth of Kazan Federal University.

The reported study was funded by RFBR according to the research project No. 17-06-00474.

The reported study was funded by RFBR and Government of the Republic of Tatarstan according to the research project No. 18-411-160011.

\section{References}

1. Aleksandrovna Maksimova Olga, Iurievna Eflova Maria, Olegovna Ermolaeva Polina "Digital Transformation as the Factor of the Generation Dynamics in the Information Society", "QUID-INVESTIGACION CIENCIA Y TECNOLOGIA", 2017, Is.28, pp.1624-1629.

2. Prensky, M. "Digital Natives, Digital Immigrants", "Horizon: MCB University Press", 2001, Vol. 9 No. 5, October, pp. 1-9.

3. Palfrey, J., Gasser, U. "Born Digital. Understanding the First Generation of Digital Natives”. Perseus Books, 2008, 375 pp.

4. Castells, M., Fernandez-Ardevol, M., Linchuan Qui, J., and Sey, A. "Mobile Communication and Society: A Global Perspective", London: MIT Press, 2007, 331 p.

5. Mead, M. "Culture and Commitment. A Study of the Generation Gap". N.Y. 1970, 91 pp.

6. Maximova, O.A, Belyaev, V.A. "Generational indigenation in a multi- ethnic and -religious society (Tatarstan, Russia), “Opcion”. 2017. Vol.33, Is.84, P.38-64.

7. Howe, N., Strauss, W. “Generations: The History of America's Future, 1584 to 2069. N.Y.: William Morrow \& Company, 1991. 554 p.

8. Goffman, E. "The Presentation of Self in Everyday Life", Edinburgh: University of Edinburgh Social Science Research Centre 1956, $161 \mathrm{p}$.

9. Turner, J. C. "Current issues in research on social identity and self-categorization theories" In N. Ellemers, R. Spears, \& B. Doosje (Eds), Social identity: Context, commitment, content. Oxford, UK. Blackwell. 1999, p. 6-34. 10. Tapscott, D. and Williams, A.D. "Wikinomics: How Mass Collaboration Changes Everything”. New York: Penguin, 2007, $320 \mathrm{p}$. 